\title{
Thermal biology in river buffalo in the humid tropics: neurophysiological and behavioral responses assessed by infrared thermography
}

\author{
Daniel Mota-Rojas $^{\text {a* }}$ (iD) | Fabio Napolitano ${ }^{\mathrm{b}}$ (i) | Ada Braghieri ${ }^{\mathrm{b}}$ (iD) | Isabel Guerrero-Legarreta ${ }^{\mathrm{c}}$ (iD) | \\ Aldo Bertoni $^{\mathrm{a}}$ | Julio Martínez-Burnes ${ }^{\mathrm{d}}$ (D) | Rosy Cruz-Monterrosa ${ }^{\text {iD }}$ | Jocelyn Gómez ${ }^{\mathrm{a}}$ | \\ Efren Ramírez-Bribiesca ${ }^{f}$ | Hugo Barrios-García ${ }^{d}$ | Nancy José ${ }^{\mid}$Adolfo Álvarez ${ }^{a}$ | \\ Patricia Mora-Medina ${ }^{\mathrm{S}}$ (D) | Agustín Orihuela
}

${ }^{a}$ Neurophysiology, behaviour and animal welfare assessment, DPAA, Universidad Autónoma Metropolitana (UAM), Xochimilco campus, 04960, Mexico City, Mexico.

${ }^{b}$ Scuola di Scienze Agrarie, Forestali, Alimentari ed Ambientali, Università degli Studi della Basilicata, 85100, Potenza, Italy.

Emeritus Professor Universidad Autónoma Metropolitana-Iztapalapa, (UAM-I), Deparment of Biotechnology: Food Science, 09340, Mexico City, Mexico.

Graduate and Research Department, Faculty of Veterinary Medicine, Universidad Autónoma de Tamaulipas, Ciudad Victoria, Tamaulipas, Mexico.

Department of Food Science. Universidad Autónoma Metropolitana (UAM-L), Campus Lerma, 52005, Lerma City, Mexico.

Livestock Production, Colegio de Postgraduados, Montecillo, 56230, Texcoco, México.

Livestock Science Department, Universidad Nacional Autónoma de México (UNAM), FESC, 54714, State of Mexico, Mexico.

Facultad de Ciencias Agropecuarias, Universidad Autónoma del Estado de Morelos, Cuernavaca, Morelos, México.

*Corresponding author:dmota@correo.xoc.uam.mx

\begin{abstract}
The present review aims to analyze the effect of extremely hot climates on the neurophysiological responses of thermal control and behavior in the river buffalo. Understanding thermal neuromodulation and its effects on the buffalo's behavior is of central importance, for this will allow us to make better decisions in terms of improving the level of welfare of buffaloes living in environments characterized by extreme heat, such as the humid tropics. The thermoregulation process involves a complex mechanism that begins with the integration of peripheral signals that are sent to the lateral parabrachial nucleus of the brainstem and then to the preoptic nucleus of the hypothalamus to generate physiological variations such as vasodilatation to dissipate heat under conditions of thermal stress, or vasoconstriction to conserve heat upon the perception of cold stimuli. The thermal biology of the river buffalo is based on several different adaptation mechanisms. The infrared thermography (IRT) technique will be of great help in this area because it permits the detection of vascular microcirculation changes in different thermal windows under adverse climatic conditions. Although buffaloes are classified as rustic animals, it is important to take into account their morpho-physiology and thermoregulation mechanisms to prevent thermal stress and the resulting poor welfare and reduced productivity. However, if appropriate thermoregulation facilities are provided (i.e., ponds, pools, potholes, or swampy areas), buffaloes can properly thermoregulate and tolerate high ambient temperatures. Therefore, they may represent a good option and an appropriate animal-based enterprise under climate change and global warming conditions.
\end{abstract}

Keywords buffalo welfare, heat dissipation, thermal behaviors, thermal changes, thermal stress, thermorregulation

\section{Introduction}

Mechanisms for regulating temperature are acquired through evolution, but only birds and mammals (homeotherms) can generate physiological responses to cold and heat. In homeotherm animals, thermoregulation involves both physiological and behavioral responses. Some mammal species have a high capacity to dissipate heat (e.g. humans, horses), while in others, the ability to sweat is limited (e.g. dogs, cats, pigs, and buffaloes have few sweat glands) or nonexistent and need to rely on different mechanisms to efficiently thermoregulate (Bradley 2013; Mota-Rojas et al 2020a,b; Casas-Alvarado et al 2020; Villanueva-García et al 2021).
Although the river buffalo (Bubalus bubalis) is a rustic animal (Guerrero-Legarreta et al 2019, 2020; CruzMonterrosa et al 2020), its productive and reproductive efficiency may be impaired when fundamental aspects related to its thermoregulating efficacy are not attended appropriately (Mitat-Valdés 2011; Mora-Medina et al 2018a; Mota-Rojas et al 2019; Bertoni et al 2019; 2020a,b; Napolitano et al 2020). This species is not exempt from the unfavorable effects and modifications of the environment; in fact, it is a mammal with specific requirements in controlling its body temperature (Church et al 2014). When river buffalo's central and peripheral thermoreceptors detect a temperature increase, species-specific physiological and behavioral changes are triggered (Marai and Haeeb 2010; 
Barros et al 2016; Gu et al 2016). These measures work together to achieve a state of thermal comfort (Aggarwal and Upadhyay 2013; Bradley 2013). Because of its scarce hair and dark skin, the river buffalo's body absorbs enormous amounts of solar radiation that make it susceptible to thermal stress (Bertoni et al 2020a,b). At the same time, this species' evaporative cooling system may be inefficient if the environmental conditions and/or farming facilities are inappropriate (Marai and Haeeb 2010; Berdugo-Gutiérrez et al 2018). For these reasons, it is important to understand the buffalo's behavioral habits and physiology and their relation to thermoregulation, the conditioning factors present in humid tropical environments, and the impact of climate change (Thornton et al 2009; Risk and Centre 2012; Weindl et al 2015; Barros et al 2016; Rojas-Downing et al 2017).

Information on thermal neuromodulation (Tan and Knight 2018; Madden and Morrison 2019) and the consequent behavioral changes will allow improving the levels of welfare and productivity of buffaloes in environments characterized by extreme heat, like the humid tropics (Barros et al 2016). The most basic thermoregulating behaviors in animals include searching for sources of cold or heat in their habitat that allow them to modify the rate of heat loss or gain. More complex thermoregulating behaviors involve the construction of nests or burrows (Terrien et al 2011) social interactions like huddling with conspecifics (Batchelder et al 1983) and specific human behaviors such as wearing clothes or using climate control devices (Tan and Knight 2018). The present review aims to analyze the effect of extremely hot climates on the neurophysiological and behavioral responses of river buffalo to achieve thermal homeostasis.

\section{Hypothalamic neuromodulation of thermoregulation}

Mammals can regulate their body temperature through both autonomous and behavioral responses. Those of the autonomous type are involuntary in origin and involve physiological processes like vasodilatation, sweating, vasoconstriction, and shivering. Behavioral responses, in contrast, are "voluntary" actions performed when mammals react to thermal discomfort (Sessler 2016). In mammals, autonomous responses to stimuli like heat and cold include mechanisms regulated by sympathetic cholinergic fibers, as in the case of sweating, or controlled by sympathetic adrenergic fibers, in the case of piloerection, vasoconstriction, and vasodilatation (Bradley 2013; Madden and Morrison 2019).

The skin has a complex sympathetic innervation system that contains multiple nervous structures, including vasodilator, vasoconstrictor, sudomotor, pilomotor, and sensory fibers or thermoreceptors (Cravello and Ferri 2008; Montanholi et al 2008; Smith and Johnson 2016). These structures transform the skin into a central organ for regulating hyperthermia, since they account for its capacity to detect changes in ambient temperature and transmit the stimuli so perceived directly to the preoptic area that, in turn, triggers a range of responses supporting thermal homeostasis (Morrison 2011, 2016). Also, nervous structures in the skin receive the nervous stimuli sent by the heat loss center and activate mechanisms such as sweating and vasodilatation (Cravello and Ferri 2008; Kanosue et al 2010). It is important to note that the activation of all these mechanisms is controlled by the release of diverse chemical substances that function as messengers within the communications network constituted by the nervous system (Smith and Johnson 2016).

When ambient temperatures increase to a point where they foster caloric stress, the buffalo's organism reacts to increase heat dissipation by evaporation through the skin or metabolic functions. The physiological mechanisms for dealing with high ambient temperatures include more significant vasodilatation to increase blood flow to the skin's surface (Casas-Alvarado et al 2020), sweating, and a faster respiratory rate (Mota-Rojas et al 2016). However, decreases in the metabolic rate can cause an imbalance in the transport and redistribution of water and electrolytes that have adverse effects on voluntary food consumption and, as a consequence, on milk production and fertility in buffalo cows (Marai and Haeeb 2010; Berdugo-Gutiérrez et al 2018; Bertoni et al 2019; Mota-Rojas et al 2019).

Figures 1 and 2 show two schematic representations of the neurophysiological response of the river buffalo when exposed to hot and cold thermal stress, respectively.

The conditions that characterize humid tropical regions include summer temperatures that can exceed $45^{\circ} \mathrm{C}$, enough to reduce the vasoconstrictor tone when the afferent stimulus that reaches the central nervous system (SNC) indicates such levels. Though we do not know precisely the thermoreceptors responsible for initiating thermoregulating signaling, it is widely believed that the temperature-sensitive transient receptor potential vanilloid (TRPV) influences the perception of different temperatures. These would include TRPV1, expressed in the brain, and TRPV3 and TRPV4, expressed in keratinocytes in the dermis. It is also thought that the TRPM 8 channels respond to the sensation of cold and trigger actions to contrast it, such as vasoconstriction, thermogenesis, and shivering (Nakamura 2011; Morrison and Nakamura 2019).

Hot signals from the environment sensitize warmreceptors in mucous membranes and the skin to generate the transmission of nervous impulses from the spinal cord's dorsal horn, where warmth-sensitive sensory neurons are activated. Those neurons then transmit the information to the lateral parabrachial nucleus (LPB) of the brainstem (Tan and Knight 2018). In particular, the dorsal subregion of the lateral parabrachial nucleus (LPBd) responds to ascending hot signals and emits a glutamatergic projection towards the preoptic area (POA) of the hypothalamus, specifically in the median preoptic nucleus ( $\mathrm{MnPO}$ ) through efferent pathways that are still under study (especially those implicated in behavioral responses).

The development of the efferent response in the form of sweating commences with the transmission of a nervous 
impulse from the POA to the rostral ventromedial medulla (RVMM), which re-transmits the signal to the intermediolateral column cells (IML) in the spinal cord. From there, the information is transmitted to the sympathetic nerves that innervate the peripheral sweat glands with the release of acetylcholine, which triggers sweating (Tan and Knight 2018).

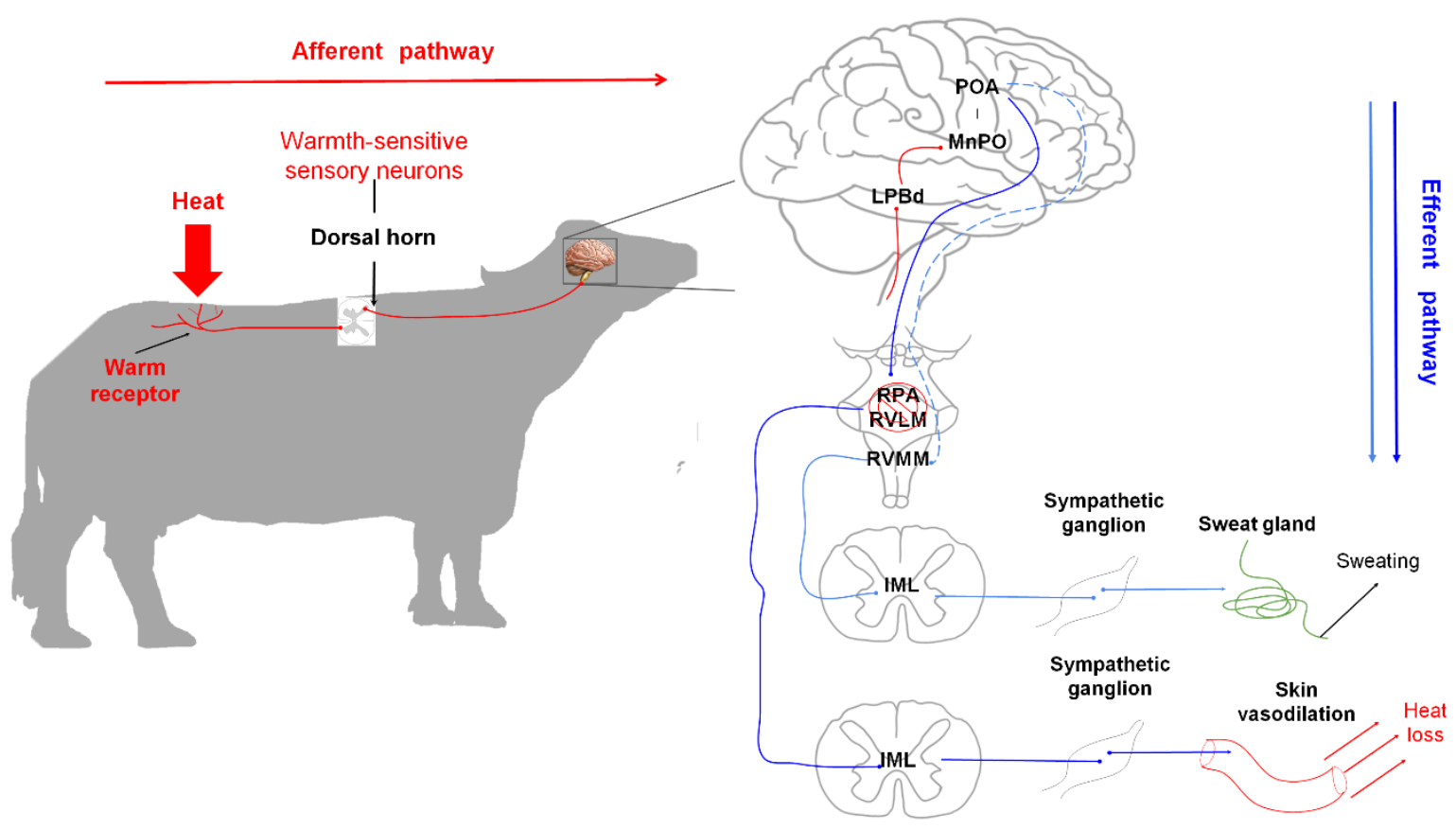

Figure 1 The river buffalo's neurophysiological mechanism of thermoregulation under conditions of heat. The afferent and efferent pathways are reported. The broken arrow indicates that the anatomical pathway connecting the POA to the RVMM is still unknown. POA, preoptic area; RPA, raphe pallidus area; RVLM, rostral ventrolateral medulla; RVMM, rostral ventromedial medulla; IML, intermediolateral column; MnPO, median preoptic nucleus; LPBd, lateral parabrachial nucleus, dorsal subregion.

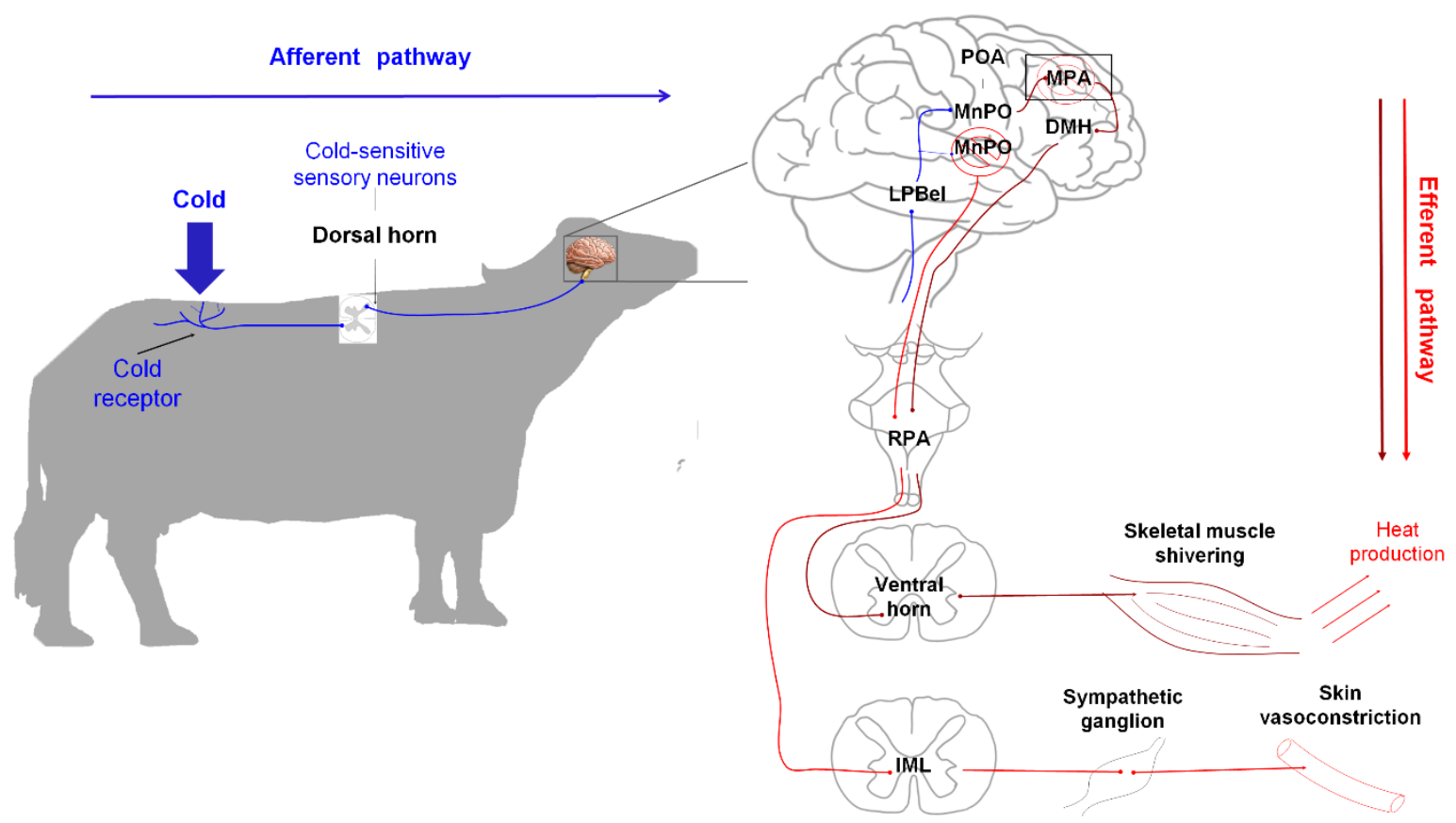

Figure 2 The river buffalo's neurophysiological mechanism of thermoregulation under conditions of cold. The afferent and efferent pathways are reported. POA, preoptic area; DMH, dorsomedial hypothalamic nucleus; RPA, raphe pallidus area; RVLM, rostral ventrolateral medulla; RVMM, rostral ventromedial medulla; IML, intermediolateral column; MnPO, median preoptic nucleus; MPA, medial preoptic area; LPBel, lateral parabrachial nucleus, external lateral subregion. 
The vasodilatation response begins with the transmission of a nervous impulse from the POA to the raphe pallidus area (RPA) and rostral ventrolateral medulla (RVLM) that inhibits the structures involved in the process of vasoconstriction (Ootsuka and McAllen 2005). A nervous impulse is transmitted to the IML neurons that, in turn, direct the signal towards the sympathetic efferent fibers which innervate the cutaneous blood vessels to trigger vasodilatation which generates heat lost via convection.

As also described for warm stimuli, cold signals from the environment sensitize cold-receptors that transmit the information along with an afferent nerve fiber to the dorsal horn of the spinal cord, where cold-sensitive sensory neurons are activated. Those neurons transmit the information to the external lateral subregion of the lateral parabrachial nucleus (LPBeL) of LPB (Tan and Knight 2018), which emits a glutamatergic projection towards the POA, specifically in the $\mathrm{MnPO}$. Once this information is received, the efferent response called thermogenesis can develop in the form of shivering. This mechanism commences with inhibition of neurons in the MPA through a signal emitted by neurons in MnPO. It allows activation of the thermogenesis-promoting neurons present in the $\mathrm{DMH}$, which sends a glutamatergic projection to the somatic premotor neurons for muscle shivering in the RPA to activate them. These, in turn, transmit a signal to the alpha and gamma motoneurons in the ventral horn of the spinal cord, which is then relayed to the efferent fibers that innervate the skeletal muscles to produce shivering and heat (Nakamura 2011; Bradley 2013; Rance et al 2013; Morrison and Nakamura 2019). During the development of peripheral vasoconstriction, the efferent pathway begins when the MnPO neurons are inhibited, as this allows the activation of the sympathetic CVC premotor neurons present in the RPA. Those neurons send glutamatergic and serotonergic projections to the preganglionic neurons of the IML, which then transmit the signal to the sympathetic efferent fibers that innervate the cutaneous blood vessels to produce vasoconstriction and thus conserve heat (Tan and Knight 2018; Madden and Morrison 2019).

Importantly, the signaling towards the POA runs in two directions, namely, to the ventral tegmental area (VTA), and the rostral ventrolateral periaqueductal gray area (rvIPAG). The reception of hot stimuli by neurons in the rvIPAG stimulates them to generate cutaneous vasodilatation that increases blood flow towards the periphery and heat dissipation via conduction and convection. At the same time, neurons in the VTA are inhibited to prevent vasoconstriction. This latter mechanism may be based on the blocking of the sympathetic premotor neurons of the medullary raphe caused by the $\gamma$-aminobutyric acid neurotransmitter (Aggarwal and Upadhyay 2013; Ootsuka and Tanaka 2015).

\section{Physiological and behavioral response to heat}

Under extreme heat conditions, the river buffalo's thermoregulating system may be inefficient, as its scarce hair offers little protection, and the high melanin content of its black skin is highly heat-absorbent, causing rapid temperature increases. Melanin particles trap ultraviolet rays and prevent damages by preventing them from penetrating through the dermis of the skin to internal layers of tissue (Bertoni et al 2019; 2020a,b). These rays are abundant in solar radiation in tropical and sub-tropical areas, so excessive exposure to the sun may be harmful to animals that, unlike buffaloes, possess scarcely pigmented skin (Ablas et al 2007; Marai and Haeeb 2010). Another relevant characteristic of this species is the density of hair follicles, which is only 135145 follicles $/ \mathrm{cm}^{2}$ versus an average of 3,000 follicles $/ \mathrm{cm}^{2}$ for Zebu cattle). This trait has a double effect; on the one hand, it facilitates heat dissipation through convection and radiation, but on the other, it exposes the skin to the direct action of solar radiation (Cravello and Ferri 2008; Zicarelli 2016). Consequently, buffaloes also have a comparatively low density of sweat glands, though are usually larger with a higher thermoregulating capacity (Zicarelli 2016, Bertoni et al 2020a,b; Guerrero Legarreta et al 2020).

As shown in Figure 3, when the river buffalo's central and peripheral thermoreceptors detect a temperature increase, they trigger the physiological and behavioral changes characteristic of this species, especially immersion in flood zones or swamps and seeking shade (Gu et al 2016). These mechanisms work together to achieve a state of thermal comfort (Aggarwal and Upadhyay 2013; Bradley 2013) by contributing to rapid heat loss, perhaps aided by this species' characteristic black skin that contains numerous blood vessels that vasodilate to facilitate heat dissipation through conduction, while the animals are immersed in mud or water. In particular, Koga et al (1999) demonstrated that buffaloes subjected to increasing environmental temperatures rise the flow of blood towards the external surface of the body thus supporting a thermoregulatory mechanism based on direct contact with the mud/water, which in turn relies on the buffalo species-specific behavior of wallowing (Figures 6 and 7). The purpose is to obtain the result that other species achieve by sweating (Khongdee et al 2011; Aggarwal and Upadhyay 2013; Oliveira et al 2013). The latter is not an efficient means of heat dissipation in tropical environments as evaporation is not favored by high environmental humidity and low day-night temperature variations. Although these mechanisms are essential for maintaining thermal equilibrium -a fundamental aspect of animal welfare- they are often neglected by producers (Sevegnani et al 2016). For instance, in an Italian study, only 15 out of 42 farms had facilities, such as pools, potholes or showers, to support thermoregulation (De Rosa et al 2009). Scientific studies have provided evidence that environmental factors exert a direct influence on the physiological variables of animals; for example, periods with high ambient temperatures have been associated with a reduction in milk production, growth, and fertility in buffaloes (Marai and Haeeb 2010), whereas the provision of facilities for thermoregulation, may promote milk production (De Rosa et al 2009). 
Figure 4 shows young buffaloes using the shade to thermoregulate. Gu et al (2016) demonstrated that providing a roof and shade reduces thermal stress, resulting in lower rectal temperatures and blood cortisol levels (Khongdee et al 2013) (Figures 10 and 11). The effects of shade translate into higher weight gain than animals kept in direct sunlight, decreased rectal temperatures, and lower respiratory rates (Castro et al 2008) and superficial temperature. Young female buffaloes exposed to direct radiation from 11:00-16:00 in the summertime show a protruding tongue, foaming at the mouth due to excessive salivation (ptyalism) and panting (hyperventilation), all signs of hyperthermia caused by caloric stress (Das et al 1999). Under free-ranging conditions (i.e.,

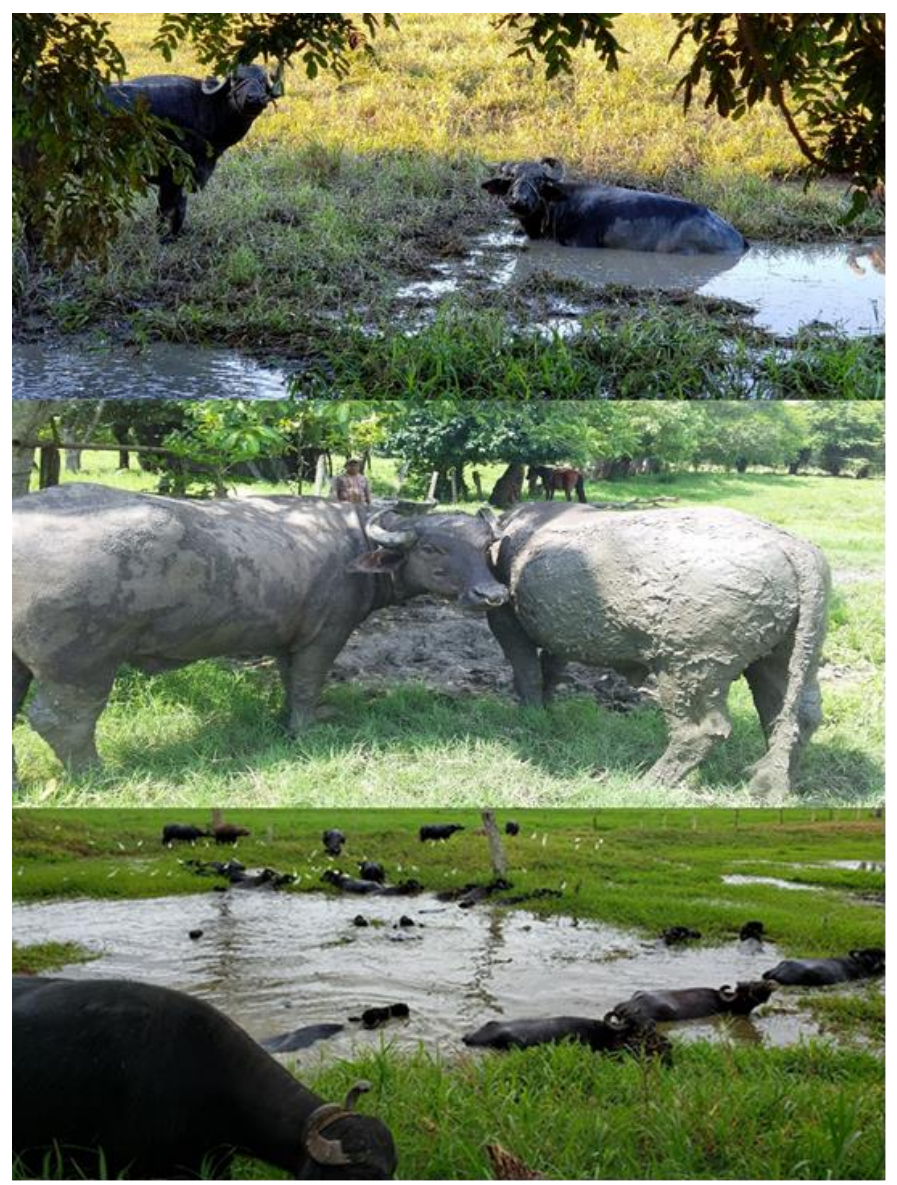

Figure 3 Thermoregulation through wallowing and muddying in water buffaloes in the humid tropics.

To efficiently thermoregulate, buffaloes spend long periods lying in the mud. This behavior is not harmful to the animals because of the high amount of sebum secreted to protect the skin (Hafez et al 1995) (Figures 6 and 7). Studies have shown that in addition to protecting the buffalo from external parasites such as ticks (De Rosa et al 2005; BerdugoGutiérrez et al 2018), immersion significantly reduces their rectal temperature, the quantity of water they ingest, production of free triiodothyronine (an indicator of metabolic changes related to variations in food ingestion associated with changes in temperature and environmental humidity), and cortisol, which has been used as a physiological extensive production systems), buffaloes' behavior is characterized by two predominant activities: feeding (ingestion, rumination) and resting. However, wallowing and muddying, especially during the hot season, are specific behaviors fundamental for thermoregulation, while protecting buffaloes from ectoparasites (Figure 3). Confinement under intensive production conditions tends to preclude some of these natural behaviors, including grazing and wallowing, while increasing the expression of undesirable behaviors, such as aggressive interactions, which constitute potential risk factors for buffalo welfare (De Rosa et al 2005; Napolitano et al 2013; Mora-Medina et al 2018b; Mota-Rojas et al 2019).

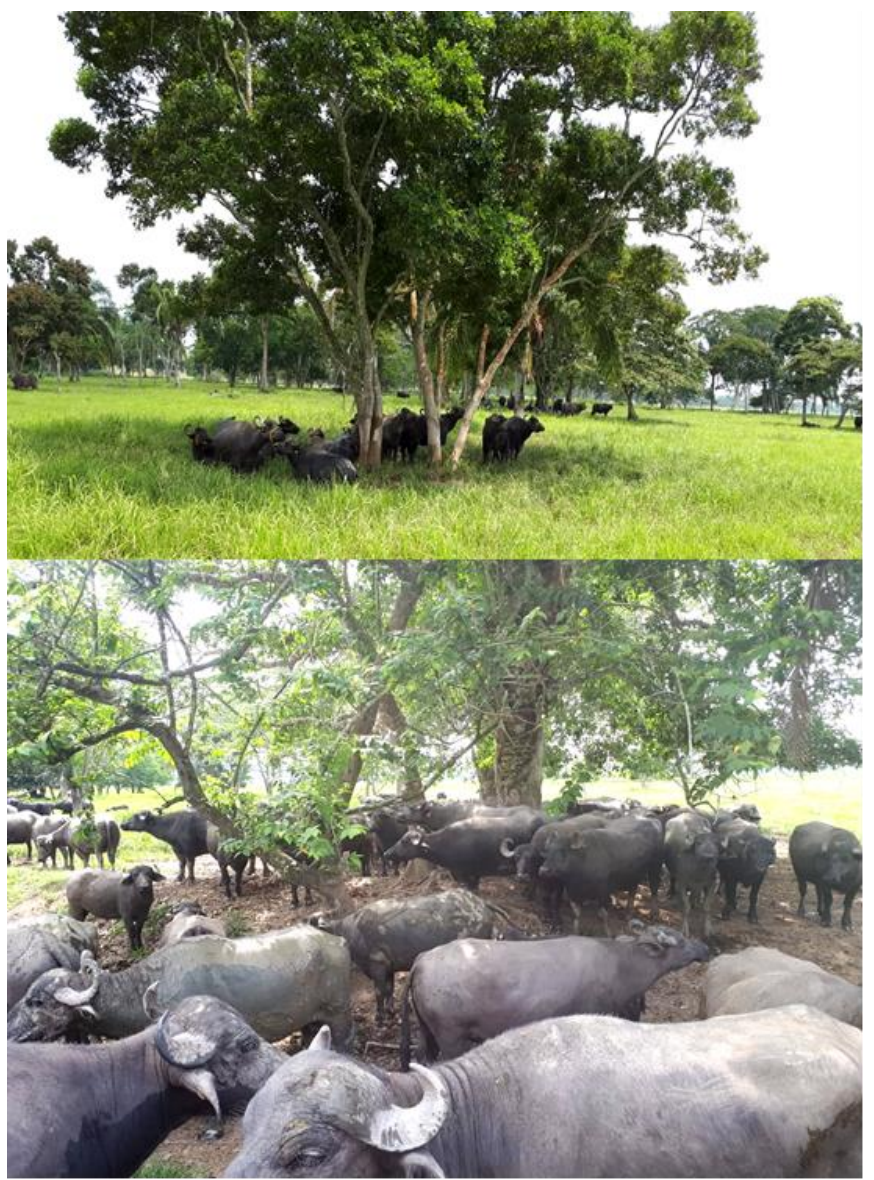

Figure 4 Use of natural tree shades by river buffaloes in the humid tropics.

biomarker of stress in buffaloes (Dimri et al 2010; Khongdee et al 2011). In buffalo bulls, high ambient temperatures may also inhibit sperm volume and motility (Silva et al 2018), whereas, in buffalo heifers, thermal stress-induced reduced feed intake, serum glucose, and cholesterol levels, while increasing serum total protein concentration (Hooda and Singh 2010).

When the body heat load exceeds the rate of heat dissipation, buffaloes suffer thermal stress (Khongdee et al 2011; Gu et al 2016), which in this species is shown by an increase in respiratory frequency as a means of increasing heat dissipation. However, in buffaloes, prolonged 
hyperventilation may induce alkalosis due to reduced blood carbon dioxide levels (Koga et al 1991). Other symptoms are excessive salivation, protrusion of the tongue, and extending the neck due to respiratory distress (Sevegnani et al 2016).

In tropical climates, buffaloes should be provided with places where they can express their typical thermoregulatory behaviors, such as ponds, potholes, and pools, or, supply facilities such as ventilators, showers, nebulizers, or sprayers providing refreshment particularly in the hottest hours of the day and on the feeding manger to promote dry matter intake (Bertoni et al 2020a,b; Guerrero-Legarreta et al 2020). Such facilities directly impact buffalo physiological state and appreciably decrease their heart rate, respiratory rate, and rectal temperature while also promoting feed ingestion and improving feeding conversion rate (Das et al 2011). However, in winter, protection from cold air currents are also required (Marai and Haeeb 2010). One technique to evaluate farm and companion animals' surface thermal dynamics is the use of infrared thermography (IRT) technique (Bertoni et al 2020a,b; Casas-Alvarado et al 2020; Mota-Rojas et al 2020a,b,c).

Figure 5 shows the average, maximum and minimum temperature values $\left({ }^{\circ} \mathrm{C}\right)$ of river buffaloes before, during, and after immersion in a swampy area, recorded using infrared thermography (IRT) technique during the hottest hour of the day in a humid tropical region in Mexico with a mean ambient summer temperature of $38{ }^{\circ} \mathrm{C}$. The buffaloes' surface temperature before entering the swamp -that is, when the animal perceived the need to cool down-exceeded $36^{\circ} \mathrm{C}$. Temperature readings show an average decrease of $1{ }^{\circ} \mathrm{C}$ upon entering the swamp, with a total reduction of around 4 ${ }^{\circ} \mathrm{C}$ upon exiting the area. These temperature readings demonstrate the contribution of wallowing behavior to heat dissipation. However, wind speed may also influence cooling by increasing evaporation and heat convection; air humidity in hot climates is another factor that can affect heat dissipation by reducing cooling through evaporation.

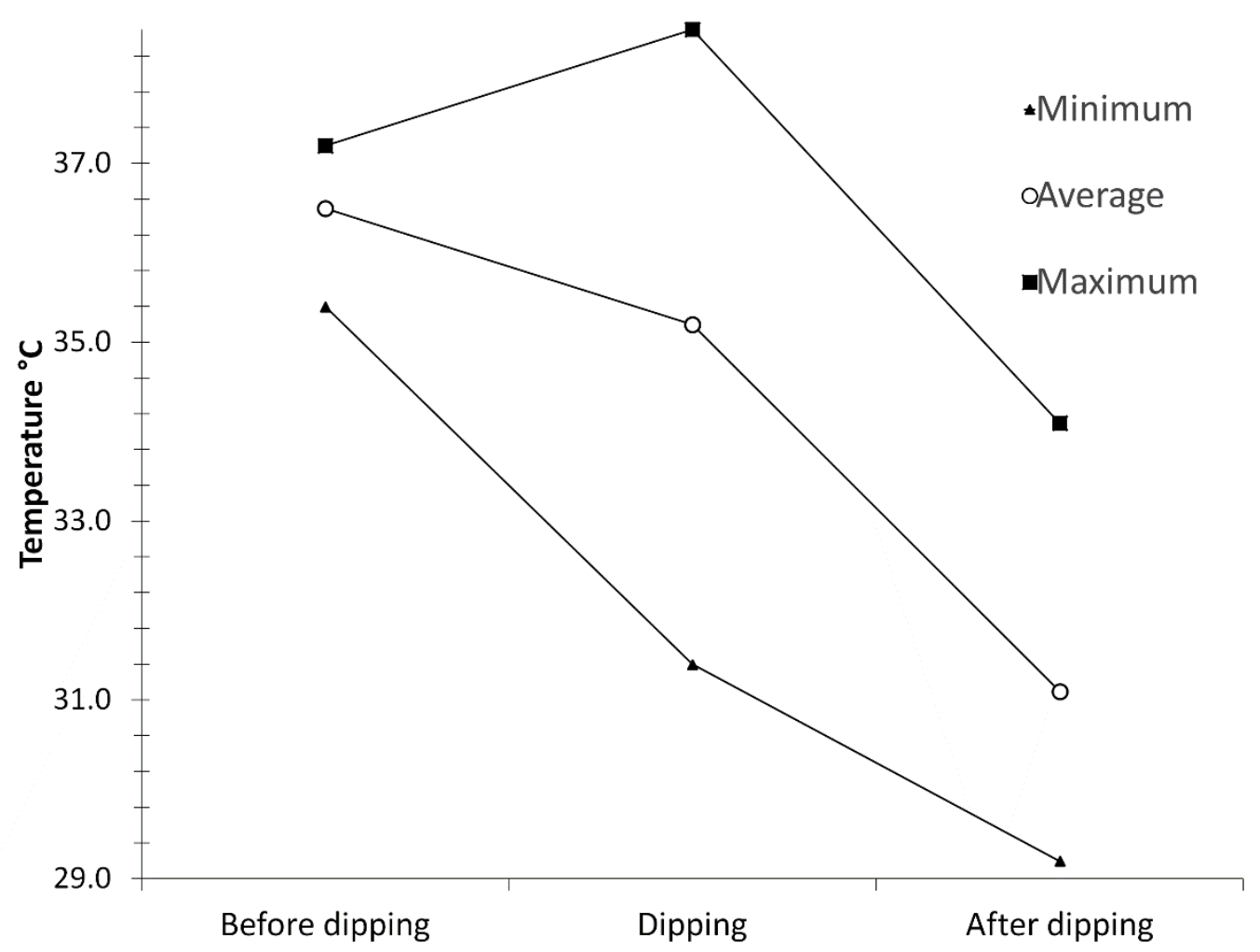

Figure $\mathbf{5}$ Thermal changes in the cutaneous microcirculation on lateral region (thoracoabdominal) of river buffalo assessed by infrared thermographic (IRT), before, during and after immersion in a swampy area in the humid tropics with a mean ambient summer temperature of $38{ }^{\circ} \mathrm{C}$.

The thermograms show the beneficial effect of the availability of swampy areas and mud for wallowing on the thermal responses of river buffaloes in Figure 6 . These thermograms were obtained through IRT, a technique used in veterinary and human medicine to quantify skin surface temperatures based on the visualization of thermographic changes (Soroko et al 2016; Tattersall 2016; Peng et al 2019; Casas-Alvarado et al 2020;). Figure 6 describes the changes in the surface temperature of a river buffalo exposed to direct solar radiation while wallowing in a marshy area and after exiting the swamp. Thermogram A shows the effect of solar radiation on the buffalo. The areas of the skin with whitish coloration indicate the highest body temperatures. The maximum temperature in the dorsal region reached $35.5^{\circ} \mathrm{C}$; in the rump, the maximum temperature was $35.1^{\circ} \mathrm{C}$, while in the thoracoabdominal region it was $36.4{ }^{\circ} \mathrm{C}$. B) While wallowing, the maximum temperature in the dorsal and rump regions increased by approximately $2.1^{\circ} \mathrm{C}$ compared to 
those same regions in thermogram $\mathrm{A}$, because these zones continued to receive solar radiation. In contrast, the maximum temperature in the thoracic region, which had significant greater contact with the mud, showed a reduction of $4{ }^{\circ} \mathrm{C}$ compared to the maximum temperature of this region in thermogram A, likely due to heat loss through conduction. C) Out of the swamp, the riverbuffalo presented a maximum temperature of $32.8^{\circ} \mathrm{C}$ in the thoracoabdominal region, quite similar to the temperature of this region when it was in the swamp, and $3^{\circ} \mathrm{C}$ lower than that of the buffalo exposed to direct solar radiation. The above suggests that mud prevents the sun's rays from directly affecting the skin, thus reducing heat gain due to radiation. These results reveal the importance of mud -fresh and dry-for the buffalo's skin since even outside the marshy area, it continued to lose heat through evaporation as the mud dried. Mud prevents heat gain due to solar radiation. The red triangles mark the zones with the highest temperatures; the blue triangles mark the areas with the lowest temperatures.

Figure 7 highlights the body areas that showed the more significant surface temperature decreases due to wallowing. This figure shows the changes in the buffalo's dermal microcirculation under exposure to the sun $(A)$; while wallowing in mud (B); and when covered with wet mud (C). Thermogram $A$ shows an extensive area of the thoracic region's surface divided into three rectangular areas that present maximum temperatures above $36.5^{\circ} \mathrm{C}$. Rectangle 1 is the warmest region $\left(39.1^{\circ} \mathrm{C}\right.$ ) because it includes the dorsal area that receives the most intense solar radiation. $\mathrm{B})$ The dorsal region (rectangle $1, \mathrm{Bx} 1$ ) continues to be the warmest zone $\left(37.5^{\circ} \mathrm{C}\right)$, while the portion covered by dry mud (rectangle $2, \mathrm{~B} \times 2$ ) registered a maximum temperature $4.4^{\circ} \mathrm{C}$ lower than the one in thermogram $A$ when the buffalo was under direct solar radiation. The abdominal region (rectangle $3, \mathrm{~B} \times 3$ ) and rump (rectangle $4, \mathrm{~B} \times 4$ ), which had more contact with the water, are the zones with the lowest maximum temperatures (31.3 and $32.5^{\circ} \mathrm{C}$, respectively). C) The buffalo covered with wet mud outside the swamp reduced its surface temperature by more than $4{ }^{\circ} \mathrm{C}$ in the areas shown, suggesting the importance of heat loss by evaporation due to moisture in the skin.

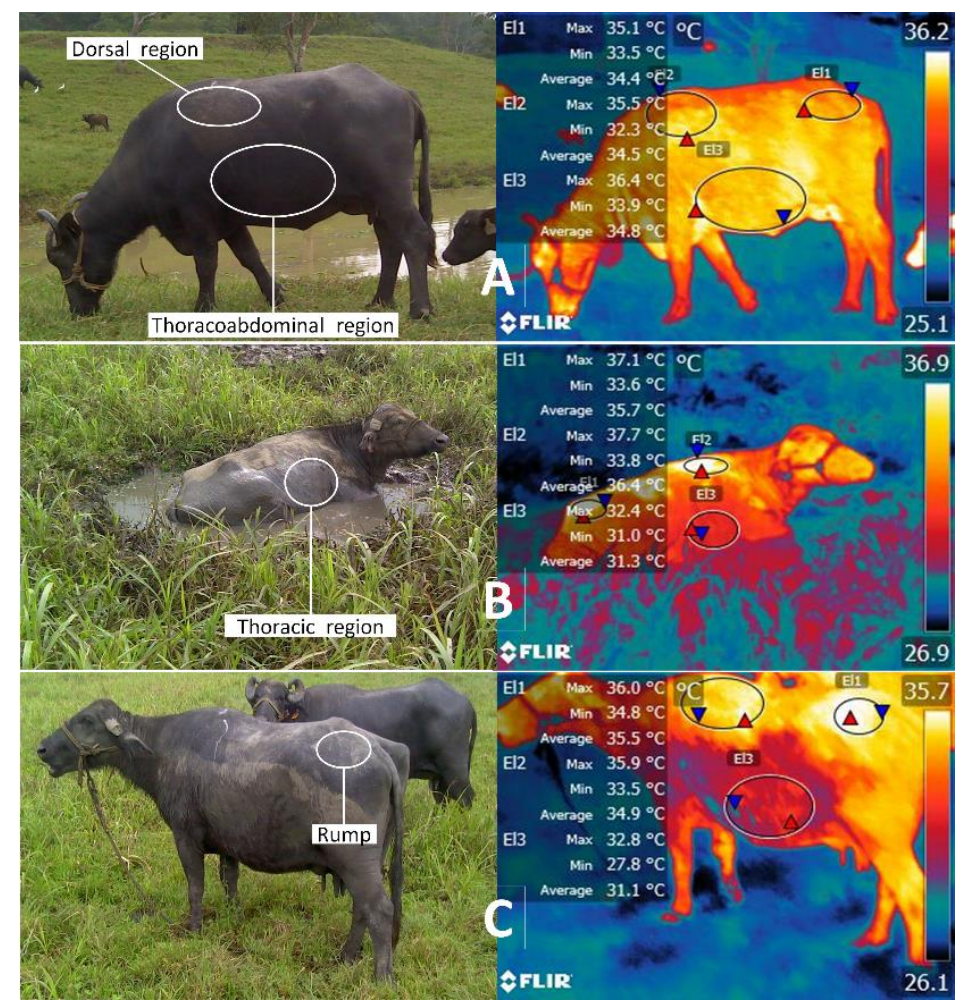

Figure 6 Changes in the cutaneous microcirculation of a river buffalo exposed to the sun before (A), during (B), and after wallowing (C). The thermographic images were taken at a distance of $2 \mathrm{~m}$ and an emissivity of 0.95 , using a FLIR E60 thermographic camera (FLIR Systems, U.S.A.) equipped with an 18-mm FOL lens. The IRT images were analyzed with FLIR Tools ${ }^{\circ}$ Software (FLIR Systems, USA).

Figure 8 illustrates the changes in the river buffalo's surface temperature due to the effect of dry mud in tropical Latin America. Thermogram A) In the dorsal region covered with dry mud, an increase of $2.7{ }^{\circ} \mathrm{C}$ was recorded in the maximum temperature compared to the reading from the animal when this area was covered with fresh mud (Figure 7, thermogram C). This emphasizes the significant impact of solar radiation. However, this temperature is still $3^{\circ} \mathrm{C}$ lower than the one recorded when the animal was exposed directly to the sun (Figure 7, thermogram A), suggesting that mud protects the skin. The abdominal region (rectangle $3, B \times 3$ ), still covered in fresh mud, presents a maximum temperature of $4.5{ }^{\circ} \mathrm{C}$ below that of the dorsal region in the same thermogram, evidence that the cutaneous process evaporation continued. B) Though no longer covered with wet mud, but only residual traces of dry mud, the buffalo had 
maximum temperatures 3.6 and $3.4{ }^{\circ} \mathrm{C}$ lower than the readings for the dorsal and ventral regions, respectively, when it was exposed to direct solar radiation without mud
(Figure 7, thermogram A). These facts demonstrate the thermoregulating effect of the riverbuffalo's characteristic wallowing behavior.

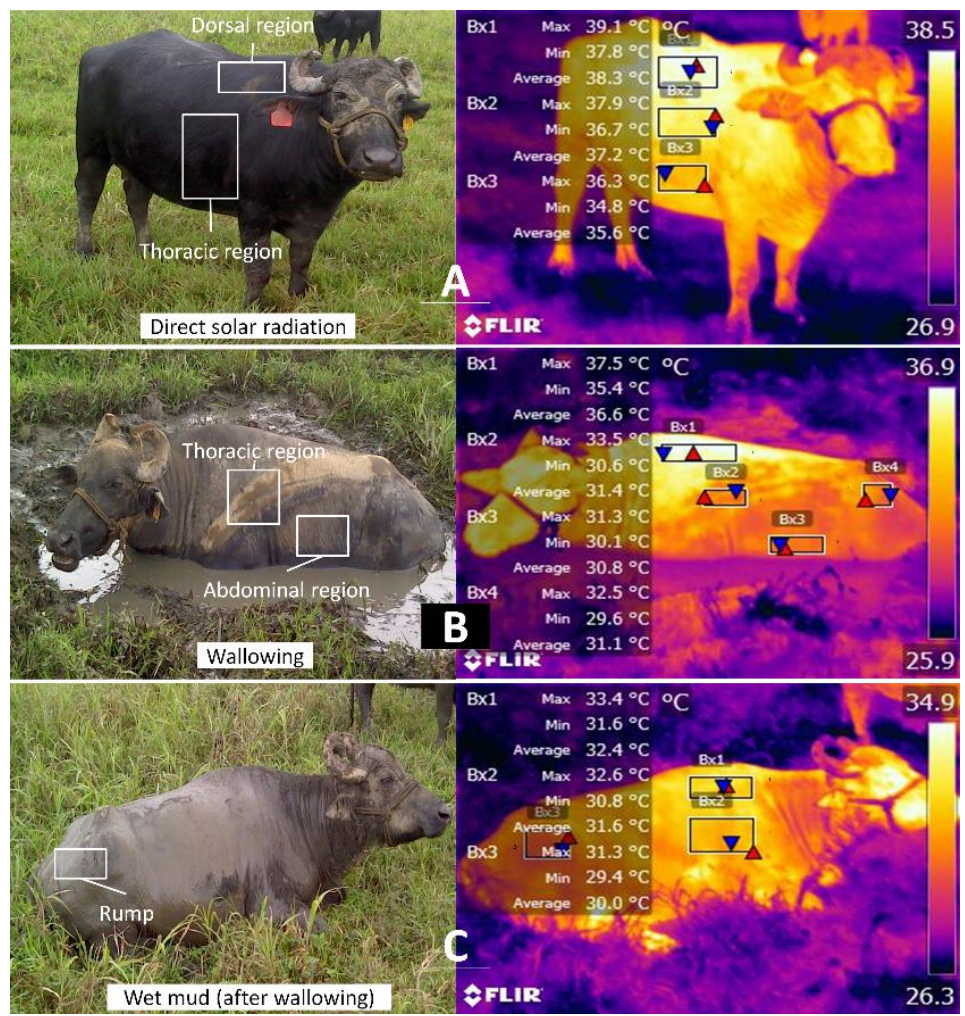

Figure 7 Identification of the body regions that show the largest temperature decrease due to the effect of the swamp and fresh mud, after the buffalo emerged. This figure shows the changes in the river buffalo's cutaneous microcirculation under exposure to the sun (A); while wallowing in mud (B); and when covered with wet mud (C). The thermographic images were taken at a distance of $2 \mathrm{~m}$ and an emissivity of 0.95 , using a FLIR E60 thermographic camera (FLIR Systems, U.S.A.) equipped with an 18-mm FOL lens. The IRT images were analyzed with FLIR Tools ${ }^{\circ}$ Software (FLIR Systems, USA).

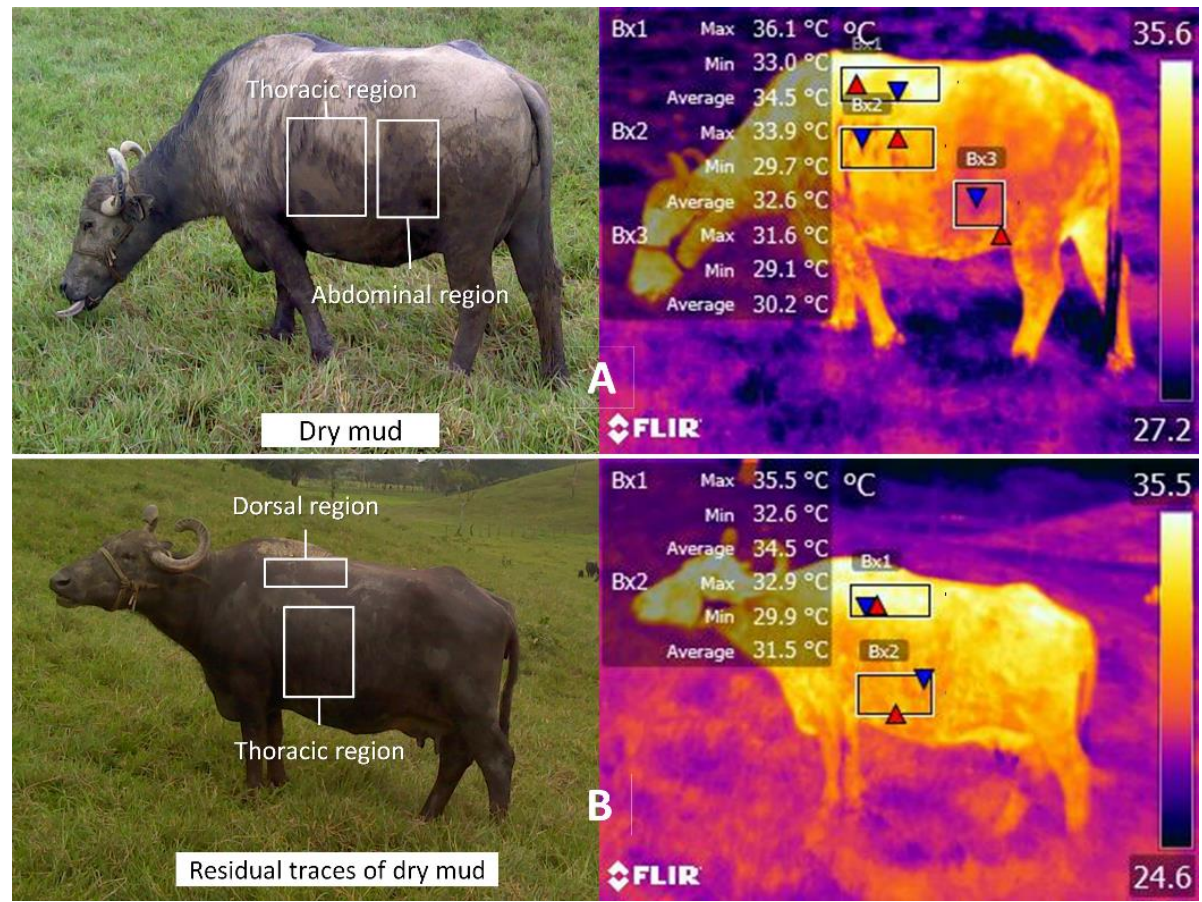

Figure 8 Identification of regions with the largest temperature decreases due to the effect of dry mud. These thermograms show the changes in the river buffalo's cutaneous microcirculation when covered with dry mud (A), and dry mud residue (B). The thermographic images were taken at a distance of $2 \mathrm{~m}$ and an emissivity of 0.95 , using a FLIR E60 thermographic camera (FLIR Systems, U.S.A.) equipped with an 18-mm FOL lens. The IRT images were analyzed with FLIR Tools ${ }^{\circ}$ Software (FLIR Systems, USA). 
Figure 9 shows the changes in surface temperature in a riverbuffalo due to the effect of direct solar radiation at different times. Thermogram A) Morning (9:30-10:30): extensive areas of the dorsal region (Bx1) exposed directly to solar radiation present a maximum temperature of $37.1^{\circ} \mathrm{C}$, while both the rump $(\mathrm{B} \times 3)$ and thoracoabdominal region (Bx2) have a maximum temperature of $34.7^{\circ} \mathrm{C}$. Thermogram B) Midday (12:00-13:00): increases of $0.6,2.6$, and $3.1^{\circ} \mathrm{C}$ are visible in the maximum temperatures of the dorsal $(\mathrm{B} \times 1)$, thoracoabdominal $(\mathrm{B} \times 2)$, and rump regions $(\mathrm{B} \times 3)$, respectively. These increases in dermal temperature are associated with the more intense solar radiation at this time of day. Thermogram C) Afternoon (16:30-17:30): all three study regions -dorsal, thoracoabdominal, rump- present reductions in their maximum temperatures of $2.3,2.3$, and $1.9{ }^{\circ} \mathrm{C}$, respectively. This may be attributable to the fact that solar radiation decreases as the day advances. Alternatively, may have resulted from the buffalo wallowing in the swamp.
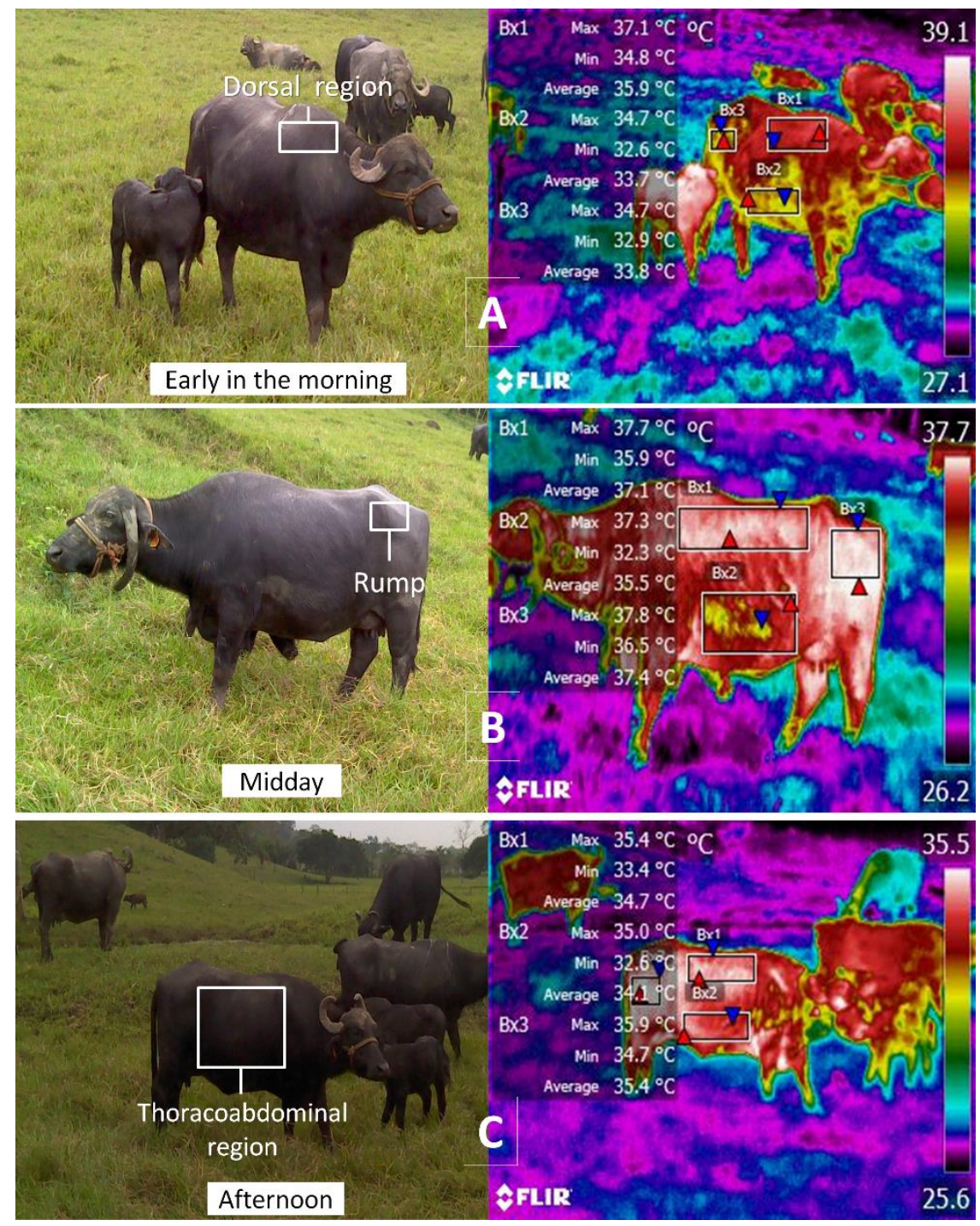

Figure 9 Changes in the dermal microcirculation of river buffaloes exposed to solar radiation at three different times of day. The thermographic images were taken at a distance of $2 \mathrm{~m}$ and an emissivity of 0.95, using a FLIR E60 thermographic camera (FLIR Systems, U.S.A.) equipped with an 18-mm FOL lens. The IRT images were analyzed with FLIR Tools ${ }^{\circledR}$ Software (FLIR Systems, USA).

Figure 10 highlights the importance of providing a roof to reduce the direct solar radiation that impacts the animals and the effect of artificial shade on cutaneous microcirculation in the riverbuffalo in tropical Latin America.

The graph in Figure 11 highlights the importance of providing a roof to provide shade for buffaloes and its beneficial effects in reducing body surface temperatures. Regardless of the thermal window, this graph shows marked decreases in surface temperatures when the buffalo is under artificial shade, compared to direct solar radiation. When the buffalo was under artificial shade, the temperature of the muzzle area, for example, decreased by $2.3{ }^{\circ} \mathrm{C}$, while the decrease on the flank (thoracoabdominal region) was $4.3^{\circ} \mathrm{C}$, and on the udder $2.1^{\circ} \mathrm{C}$, compared to these regions in river buffaloes exposed to direct solar radiation. Several studies (e.g. Paciullo et al 2011; Mohankumar et al 2012; Kamal et al 2016; Llamas-Luceño et al 2020) have demonstrated the favorable effects of shade not only concercingthe welfare and comfort of ruminants but also in terms of increased productivity and reproductive efficiency. 


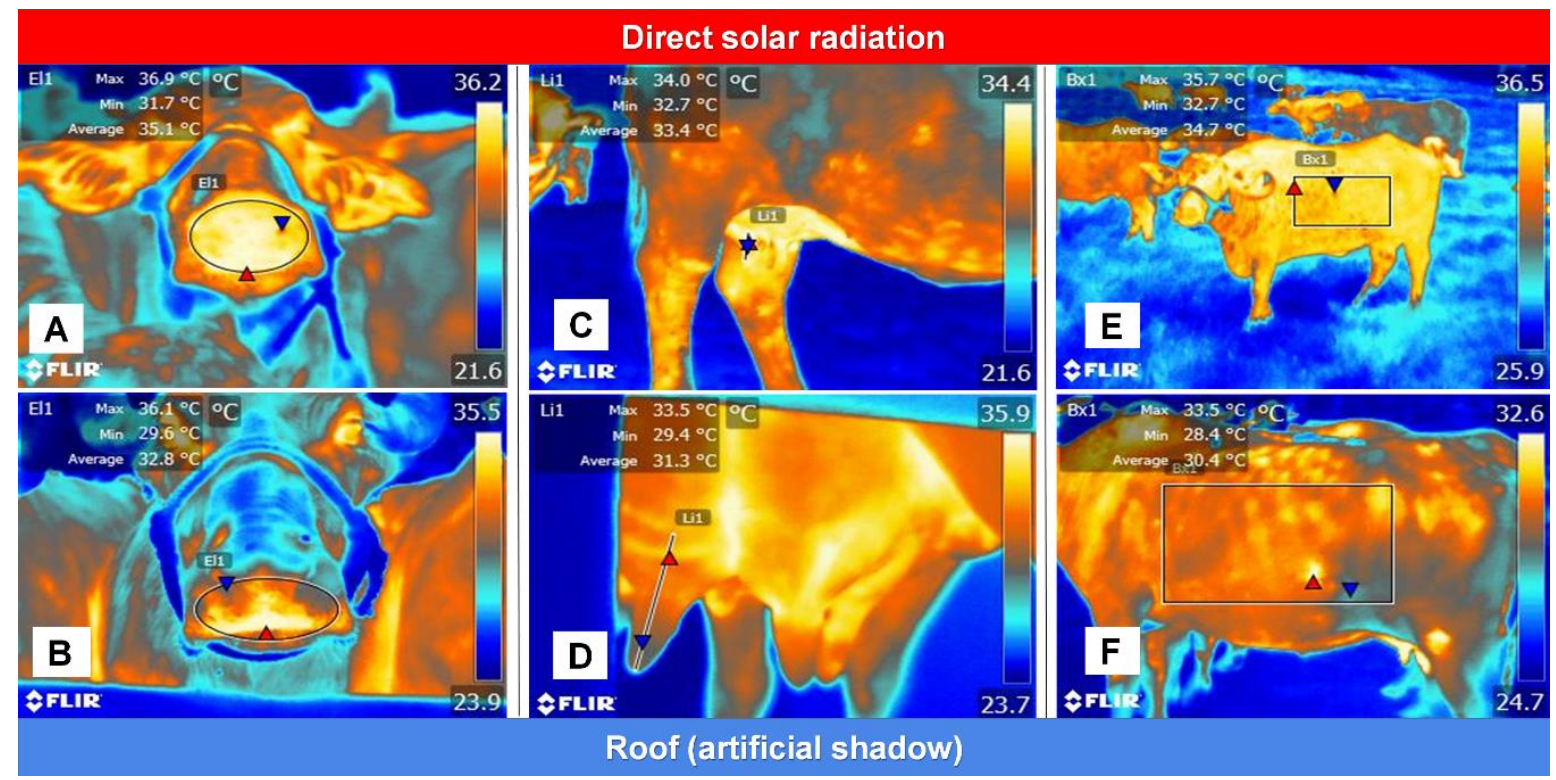

Figure 10 Effect of artificial shade provided by a roof on changes in dermal microcirculation in the river buffalo. A) shows the muzzle under direct exposure to the sun, revealing an increase in the average temperature of $2.3^{\circ} \mathrm{C}$ (to $35.1^{\circ} \mathrm{C}$ ) compared to Figure B) ( $32.8^{\circ} \mathrm{C}$ ) for the muzzle of a buffalo under a roof that offers artificial shade. Thermogram C) illustrates the effect of solar radiation on the temperature of the teat (Li1). The average temperature of the teat exposed to solar radiation was $33.4{ }^{\circ} \mathrm{C}$, compared to $31.3^{\circ} \mathrm{C}$ for the teat of the buffalo under the artificial shade of a roof (D, Li1). Thermographic image $\mathrm{E}$ ) shows an average temperature of $34.7^{\circ} \mathrm{C}$ in the lateral region of the water buffalo exposed to direct solar radiation, while in thermogram $\mathrm{F}$ ), the buffalo under artificial shade shows a marked temperature reduction of $4.3^{\circ} \mathrm{C}$ in this region of the body. The thermographic images were taken at a distance of $2 \mathrm{~m}$ and an emissivity of 0.95, using a FLIR E60 thermographic camera (FLIR Systems, U.S.A.) equipped with an 18-mm FOL lens. The IRT images were analyzed with FLIR Tools ${ }^{\circ}$ Software (FLIR Systems, USA).

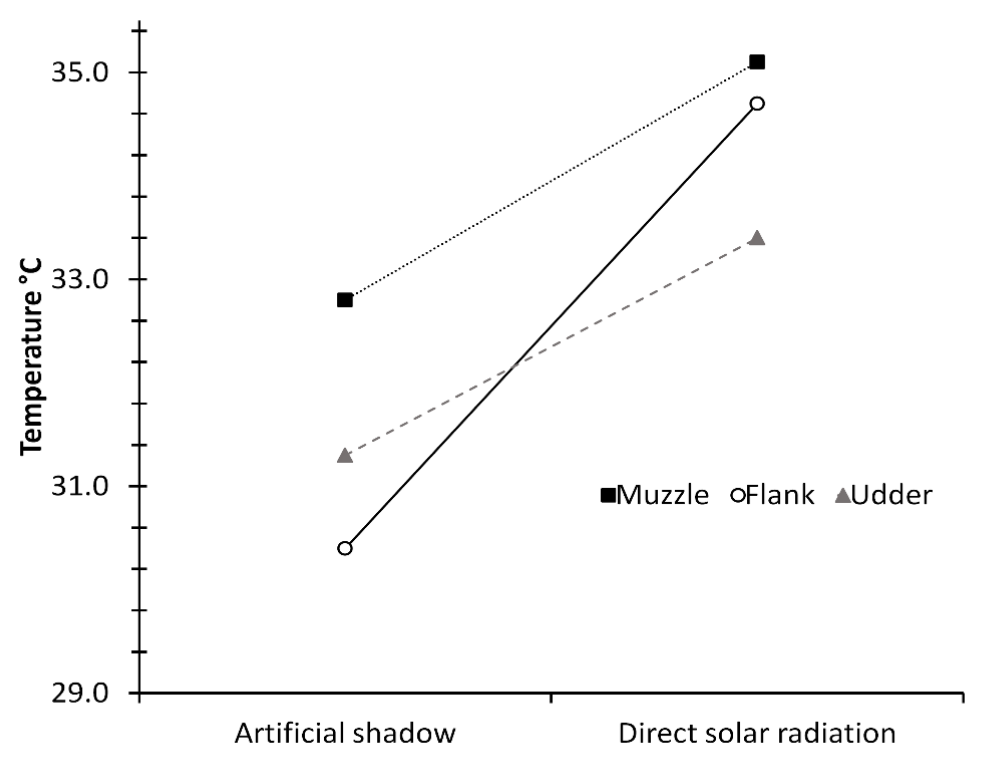

Figure 11 Importance of providing artificial shade for changes in cutaneous microcirculation in the river buffalo. Thermal changes in the cutaneous microcirculation on muzzle, flank and udder of river buffalo assessed by infrared thermographic (IRT). In this graph highlights the importance of providing a roof to provide shade for buffaloes.

\section{Final Considerations}

Understanding thermal neuromodulation and its effects on the behavior of the buffalo is of central importance, allowing us to make appropriate decisions to improve the level of welfare of buffaloes living in environments characterized by extreme heat, such as the humid tropics. The thermoregulation process involves a complex mechanism that begins with the integration of peripheral signals that are sent to the lateral parabrachial nucleus of the brainstem and then to the preoptic nucleus of the hypothalamus to generate physiological variations such as vasodilatation to dissipate heat under conditions of thermal stress, or vasoconstriction to conserve heat upon the perception of cold stimuli. 
The thermal biology of the river buffalo requires further investigation. The IRT technique will be of great help in this area because it permits the detection of changes in vascular microcirculation in different thermal windows under diverse climatic conditions. Although buffaloes are considered as a rustic species, it is vital to take into account their morpho-physiology and thermoregulation mechanisms, while also recognizing the importance of shade, flood zones, and swamps, to prevent conditions of thermal stress that can result in deficient levels of welfare and production. At the same time, if appropriate facilities for thermoregulation are provided (i.e., ponds, pools, potholes, or swampy areas), buffaloes can properly thermoregulate and tolerate high ambient temperatures. Therefore, they may represent a good option and an appropriate animal-based enterprise under climate change and global warming conditions.

\section{Conflict of Interest}

The authors declare that they have no conflict of interest.

\section{Funding}

This research did not receive any financial support.

\section{References}

Ablas DDS, Titto EAL, Pereira AMF, Titto CG, da Cunha Leme T (2007) Comportamento de Bubalinos a pasto frente a disponibilidade de sombra e água para imersão. Ciência Animal Brasileira 8:167-175.

Aggarwal A, Upadhyay R (2013) Stress, heat productivity, animal. In: Stress, heat productivity, animal. Springer-Verlag, pp 1-25.

Barros DV, Silva LKX, Kahwage PR, Laurenco Junior JB, Dousa JS, Franco IM, Martorano LG, Garcia AR (2016) Assessment of surface temperatures of buffalo bulls (Bubalus bubalis) raised under tropical conditions using infrared thermography. Arquivo Brasileiro de Medicina Veterinária e Zootecnia 68:422-430.

Batchelder P, Kinney RO, Demlow L, Lynch CB (1983) Effects of temperature and social interactions on huddling behavior in Mus musculus. Physiology and Behaviour 31:97-102

Berdugo-Gutiérrez J., Napolitano F., Mota-Rojas (2018) El Búfalo de Agua y el Estrés Calórico - BM Editores. In: Spec. Sect. Let's Learn Anim. Welf. together. BM Ed. Press. Mex. City. Mex. https://bmeditores.mx/seccionesespeciales/el-bufalo-de-agua-y-el-estres-calorico-1877/. Accessed 13 Aug 2019.

Bertoni A, Álvarez-Macias A, Mota-Rojas D (2019) Productive performance of buffaloes and their development options in tropical regions. Sociedades Rurales Producción y Medio Ambiente 19:59-80.

Bertoni A, Napolitano F, Mota-Rojas D, Sabia E, Alvarez A, Mora P, Morales A, Berdugo J, Guerrero-Legarretra I (2020a) Similarities and differences between river buffaloes and cattle: health, physiological, behavioural and productivity aspects. Journal of Buffalo Science 9:92-109.

Bertoni A, Mota-Rojas D, Álvarez-Macias A, Mora-Medina P, GuerreroLegarreta I, Morales-Canela A, Gómez-Prado J, José-Pérez N, MartínezBurnes J (2020b) Scientific findings related to changes in vascular microcirculation using infrared thermography in the river buffalo. Journal of Animal Behaviour and Biometeorology 8:288-297.

Bradley G. (2013) Cunningham's Textbook of Veterinary Physiology, Fifth ed. Elsevier, Spain.

Casas-Alvarado A, Mota-Rojas D, Hernández-Ávalos I, Mora P, Olmos HÁ, Verduzco A, Reyes B, Martínez-Burnes J (2020) Advances in infrared thermography: Surgical aspects, vascular changes, and pain monitoring in veterinary medicine. Journal of Thermal Biology 92:102664.

Castro AC, Lourenço Júnior J de B, Santos N de FA dos (2008) Sistema silvipastoril na Amazônia: ferramenta para elevar o desempenho produtivo de búfalos. Ciência Rural 38:2395-2402.

Church JS, Hegadoren PR, Paetkau MJ, Miller CC, Regev-Shoshani G, Schaefer AL, Schwartzkopf-Genswein KS (2014) Influence of environmental factors on infrared eye temperature measurements in cattle. Research in Veterinary Science 96:220-226.

Cravello B, Ferri A (2008) Relationships between skin properties and environmental parameters. Skin Research and Technology 14:180-186.

Cruz-Monterrosa RG, Mota-Rojas D, Ramírez-Bibriesca E, Mora-Medina P, Guerrero-Legarreta I (2020) Scientific findings on the quality of river buffalo meat and it's prospects for future studies. Journal of Buffalo Science 9:170180.

Das KS, Singh G, Paul SS, Malik R, Oberoi P, Deb S (2011) Physiological responses and performance of Nili-Ravi buffalo calves under different washing frequency during hot summer months in tropics. Tropical Animal Health and Production 43:35-39.

Das S., Upadhyay R., Madan M. (1999) Heat stress in Murrah buffalo calves. Livest Prod Sci 61:71-78.

De Rosa G, Grasso F, Braghieri A, Bilancione A, Di Francia A, Napolitano F (2009) Behavior and milk production of buffalo cows as affected by housing system. Journal of Dairy Science 92:907-912.

De Rosa G, Napolitano F, Grasso F, Pacelli C, Borde A (2005) On the development of a monitoring scheme of buffalo welfare at farm level. Italian Journal of Animal Science 4:115-125.

Dimri U, Ranjan R, Sharma MC, Varshney VP (2010) Effect of vitamin E and selenium supplementation on oxidative stress indices and cortisol level in blood in water buffaloes during pregnancy and early postpartum period. Tropical Animal Health and Production 42:405-410.

Gu Z, Yang S, Leng J (2016) Impacts of shade on physiological and behavioural pattern of Dehong buffalo calves under high temperature. Applied Animal Behaviour Science 177:1-5.

Guerrero-Legarreta I, Napolitano F, Mota-Rojas D (2019) El búfalo de agua, versatil y rústico como productor de carne. Agro Meat. Buenos Aires, Argentina 2019; Febrero: 1-10.

Guerrero-Legarreta I, Napolitano F, Cruz-Monterrosa R, Mota-Rojas D, Mora P, Ramírez-Bribiesca E, Bertoni A, Berdugo J, Braghieri A (2020) A River buffalo meat production and quality: sustainability, productivity, chemical composition and sensory properties. Journal of Buffalo Science 9:159-169.

Hafez E, Badreldin A, Shafie M (1995) Skin structure of Egyptian buffalo and cattle with particular reference to sweat glands. Journal Agriculture Science 46:19-30.

Hooda OK, Singh G (2010) Effect of Thermal Stress on Feed Intake, Plasma Enzymes and Blood Biochemicals in Buffalo Heifers. Indian Journal of Animal Nutrition 27:122-127.

Kamal R, Dutt T, Patel M (2016) Behavioural, biochemical and hormonal responses of heat-stressed crossbred calves to different shade materials. Applied Animal Behaviour Science 44:347-354.

Kanosue K, Crawshaw LI, Nagashima K, Yoda T (2010) Concepts to utilize in describing thermoregulation and neurophysiological evidence for how the system works. European Journal Applied Physiology 109:5-11.

Khongdee T, Sripoon S, Vajrabukka C (2011) The effects of high temperature and wallow on physiological responses of swamp buffaloes (Bubalus bubalis) during winter season in Thailand. Journal of Thermal Biology 36:417-421.

Khongdee T, Sripoon S, Vajrabukka C (2013) The effects of high temperature and roof modification on physiological responses of swamp buffalo (Bubalus bubalis) in the tropics. International Journal of Biometeorology 57:349-354.

Koga A, Chikamune T, Kanai Y (1991) Effects of High Environmental Temperatures on Some Physicochemical Parameters of Blood and Heat Production in Swamp Buffaloes and Holstein Cattle. Animal Science and Technology 62:1022-1028.

Koga A, Kurata K, Ohata K, M. Nakajima, Hirose H, Furukawa R, Kanai Y, Chikamune $T$ (1999) Internal changes of blood compartment and heat distribution in swamp buffaloes under hot conditions: comparative study of thermo-regulation in buffaloes and friesian cows. Asian-Australasian Journal of Animal Sciences 12:886-890. 
Llamas Luceño N, de Souza Ramos Angrimani D, de Cássia Bicudo L (2020) Exposing dairy bulls to high temperature-humidity index during spermatogenesis compromises subsequent embryo development in vitro. Theriogenology 141:16-25.

Madden CJ, Morrison SF (2019) Central nervous system circuits that control body temperature. Neuroscience Letter 696:225-232.

Marai IFM, Haeeb AAM (2010) Buffalo's biological functions as affected by heat stress - A review. Livestock Science 127:89-109.

Mitat-Valdés A (2011) Antecedentes y perspectivas de la actividad bufalina en el trópico. Revista de Tecnología en Marcha 24: 121.

Mohankumar SMJ, Balasubramanian P, Dharmaraj M, Mohankumar PS (2012) Neuroendocrine regulation of adaptive mechanisms in livestock. In: Environmental Stress and Amelioration in Livestock Production. SpringerVerlag Berlin Heidelberg, pp 263-298.

Montanholi YR, Odongo NE, Swanson KC, Schenkel F, McBride B, Miller S, (2008) Application of infrared thermography as an indicator of heat and methane production and its use in the study of skin temperature in response to physiological events in dairy cattle (Bos taurus). Journal of Thermal Biology 33:468-475.

Mora-Medina P, Berdugo-Gutiérrez JA, Mota-Rojas D, Ruiz J, Nava J, Guerrero-Legarreta I (2018a) Behaviour and welfare of dairy buffaloes: pasture or confinement? Journal of Buffalo Science 7:43-48.

Mora-Medina P, Napolitano F, Mota-Rojas D, Berdugo J, Ruiz J, GuerreroLegarreta I (2018b) Imprinting, Sucking and Allosucking Behaviors in Buffalo Calves. Journal of Buffalo Science 7:49-57.

Morrison SF (2011) 2010 Carl Ludwig Distinguished Lectureship of the APS Neural Control and Autonomic Regulation Section: Central neural pathways for thermoregulatory cold defense. Journal of Applied Physiology 110:11371149.

Morrison SF (2016) Central neural control of thermoregulation and brown adipose tissue. Auton Neuroscience 196:14-24.

Morrison SF, Nakamura K (2019) Central Mechanisms for Thermoregulation. Annual Review Physiology 81:285-308.

Mota-Rojas D, Velarde A, Maris-Huertas S, Cajiao-Pachón M. (2016) Animal welfare, a global vision in Ibero-America. [Bienestar Animal una visión global en Iberoamérica]. 3rd edn. Elsevier, Barcelona, Spain.

Mota-Rojas D, De Rosa G, Mora-Medina P, Braghieri A, Guerrero-Legarreta I, Napolitano F (2019) Invited review: Dairy buffalo behaviour and welfare from calving to milking. CAB Reviews: Perspectives in Agriculture, Veterinary Science, Nutrition and Natural Resources 1-9. doi: 10.1079/PAVSNNR201914035

Mota-Rojas D, Martínez-Burnes J, Napolitano F, et al (2020a) Invited Review: Dystocia: factors affecting parturition in domestic animals. CAB Reviews: Perspectives in Agriculture, Veterinary Science, Nutrition and Natural Resources 15:1-16.

Mota-Rojas D, Olmos-Hernández A, Verduzco-Mendoza A, Lecona-Butrón $H$, Martínez-Burnes J, Mora-Medina P, Gómez-Prado PJ, Orihuela A (2020b) Infrared thermal imaging associated with pain in laboratory animals. Experimental Animals doi: 10.1538/expanim.20-0052

Mota-Rojas D, Broom DM, Orihuela A, Velarde A, Napolitano N, AlonsoSpilsbury M (2020c) Effects of human-animal relationship on animal productivity and welfare. Journal of Animal Behaviour and Biometeorology 8:196-205.

Nakamura K (2011) Central circuitries for body temperature regulation and fever. American Journal of Physiology Integrative Comparative Physiolology 301:R1207-R1228.

Napolitano F, Arney D, Mota-Rojas D, De Rosa G (2020) Chapter 17. Reproductive technologies and animal welfare. In: Presicce G (ed) Reproductive technologies in animals., 1st edn. S\&T Sciences/Elsevier Press, Italy, p 266

Napolitano F, Pacelli C, Grasso F, Braghieri A, De Rosa G (2013) The behaviour and welfare of buffaloes (Bubalus bubalis) in modern dairy enterprises. Animal 7:1704-1713.

Oliveira JPF, Rangel AHN, Barreto MLJ, Araujo V, Lima Junior D, Novaes LP, Oliveira JPF, Rangel AHN, Barreto MLJ, Araújo VM, Lima Júnior DM, Novaes
LP, Aureliano IPL (2013) Temperamento de búfalas em sala de ordenha sobre índices produtivos e adaptabilidade ao ambiente: uma revisão. Journal of Animal Behaviour and Biometeorology 1:21-30.

Ootsuka Y, McAllen RM (2005) Interactive drives from two brain stem premotor nuclei are essential to support rat tail sympathetic activity. American Journal of Physiology Integrative Comparative Physiolology 289:R1107-R1115.

Ootsuka Y, Tanaka M (2015) Control of cutaneous blood flow by central nervous system. Temperature 2:392-405.

Paciullo DSC, de Castro CRT, Gomide CA de M, Mauricio RM, Avila Pires MF Dias Muller M (2011) Performance of dairy heifers in a silvopastoral system. Livestock Science 141:166-172.

Peng D, Chen S, Li G, Cheng J, Wang J, Gu X (2019) Infrared thermography measured body surface temperature and its relationship with rectal temperature in dairy cows under different temperature-humidity indexes. International Journal of Biometeorology 63:327-336.

Rance NE, Dacks PA, Mittelman-Smith MA, Romanovsky AA, Krajewski-Hall SJ (2013) Modulation of body temperature and LH secretion by hypothalamic KNDy (kisspeptin, neurokinin B and dynorphin) neurons: A novel hypothesis on the mechanism of hot flushes. Frontiers in Neuroendocrinology 34:211227.

Risk LM, Centre VA (2012) The impact of climate change on livestock production amongst the resource-poor farmers of third world countries: A Review. Asian Journal Agriculture Rural Development 2:621-631.

Rojas-Downing MM, Nejadhashemi AP, Harrigan T, Woznicki SA (2017) Climate change and livestock: impacts, adaptation, and mitigation. Climate Risk Management 16:145-163.

Sessler DI (2016) Perioperative thermoregulation and heat balance. Lancet 387:2655-2664.

Sevegnani KB, Fernandes DPB, Silva SHM-G da (2016) Evaluation of thermorregulatory capacity of dairy buffaloes using infrared thermography. Engenharia Agrícola 36:1-12.

Silva LKX, Sousa JS, Silva AOA (2018) Testicular thermoregulation, scrotal surface temperature patterns and semen quality of water buffalo bulls reared in a tropical climate. Andrologia 50:e12836.

Smith CJ, Johnson JM (2016) Responses to hyperthermia. Optimizing heat dissipation by convection and evaporation: Neural control of skin blood flow and sweating in humans. Auton Neuroscience 196:25-36.

Soroko M, Howell K, Zwyrzykowska A, Dudek K, Zielińska P, Kupczyński R (2016) Maximum Eye Temperature in the Assessment of Training in Racehorses: Correlations With Salivary Cortisol Concentration, Rectal Temperature, and Heart Rate. Journal of Equine Veterinary Science 45:3945.

Tan CL, Knight ZA (2018) Regulation of Body Temperature by the Nervous System. Neuron 98:31-48.

Tattersall GJ (2016) Infrared thermography: A non-invasive window into thermal physiology. Comparative Biochemistry and Physiology Part A: Molecular and Integrative Physiology 202:78-98.

Terrien J, Perret M, Aujard F (2011) Behavioral thermoregulation in mammals: a review. Frontiers in Bioscience 16:1428.

Thornton PK, van de Steeg J, Notenbaert A, Herrero M (2009) The impacts of climate change on livestock and livestock systems in developing countries: A review of what we know and what we need to know. Agriculture System 101:113-127.

Villanueva-García D, Mota-Rojas D, Martínez-Burnes J, Mora MP, Salmeron C, Gómez J, Boscato L, Gutiérrez O, Reyes, B, González-Lozano M (2021) Hypothermia in newly born piglets: Mechanisms of thermoregulation and pathophysiology of death. Journal of Animal Behaviour and Biometeorology 9:2101.

Weindl I, Lotze-Campen H, Popp A, Müller C, Havlík P, HerreroM, Schmitz C, Rolinski S (2015) Livestock in a changing climate: production system transitions as an adaptation strategy for agriculture. Environmental Research Letters 10:094021.

Zicarelli L (2016) Estacionalidad Reproductiva en Búfalas. In: Crudeli G (ed) Reproducción en Búfalas. Ediciones. Moglia, Argentina. 